\title{
Beliefs related to oral antidiabetic use among individuals with diabetes
}

\author{
Crenças relacionadas ao uso de antidiabético oral em pessoas com diabetes \\ Creencias relacionadas con el uso antidiabético oral en personas con diabetes
}

Bernadete de Lourdes André Gouveia ${ }^{1}$ (C) Mailson Marques de Sousa ${ }^{1}$ (i) Taciana da Costa Farias Almeida ${ }^{1}$ (1) Vinicius André Gouveia de Sousa ${ }^{1}$ (1)

Wilma Dias de Fontes Pereira ${ }^{1}$ (1) Simone Helena dos Santos Oliveira ${ }^{1}(1)$

1. Universidade Federal da Paraíba. João Pessoa, PB, Brasil.

\section{Abstract}

Objective: To identify beliefs related to oral antidiabetic use among individuals with type 2 diabetes mellitus, based on the Theory of Planned Behavior. Method: This is a descriptive, quantitative and qualitative study conducted with 32 participants using oral antidiabetic drugs. Data was collected through an open question tool and analyzed by number of emissions and content. Results: Among the behavioral beliefs, the following stand out: (a) as an advantage, to keep diabetes controlled; and (b) as disadvantages, gastric pain and discomfort, nausea and diarrhea. In the normative beliefs, family stood out as a social referent (children, mother and siblings). As for the control beliefs, taking the tablets with water and the size of the tablets stood out as practicalities and difficulties, respectively, in relation to the oral therapy follow-up. Conclusion and implications for practice: It was possible to identify the beliefs regarding the behavior of taking oral antidiabetics that will contribute to foster educational strategies with the potential to strengthen the positive beliefs and to revert the negative ones, in favor of adherence to drug therapy, glycemic control and quality of life.

Keywords: Beliefs; Behavior; Type 2 diabetes mellitus; Pharmacological treatment

\section{Resumo}

Objetivo: Identificar as crenças relacionadas ao uso de antidiabético oral em pessoas com diabetes mellitus tipo 2 , com base na Theory of Planned Behavior. Método: Estudo descritivo com abordagem quantiqualitativa, realizado com 32 participantes em uso de antidiabético oral. Os dados foram coletados por meio de formulário com perguntas abertas e analisados pelo número de emissões e conteúdo. Resultados: Entre as crenças comportamentais, destacam-se: como vantagem, manter o diabetes controlado; e, como desvantagens, dor e desconforto gástrico, enjoo e diarreia. Nas crenças normativas, sobressaiu como referente social a família (filhos, mãe e irmãos). Quanto às crenças de controle, tomar os comprimidos com água e o tamanho dos comprimidos como as facilidades e dificuldades, respectivamente, em relação ao seguimento da terapêutica oral. Conclusão e implicações para prática: Foi possível identificar as crenças frente ao comportamento da tomada do antidiabético oral que contribuirão para fomentar estratégias educativas com poder de fortalecer as positivas e reverter as negativas, em benefício da adesão à terapêutica medicamentosa, ao controle glicêmico e à qualidade de vida.

Palavras-chave: Crenças; Comportamento; Diabetes mellitus tipo 2; Tratamento farmacológico.

\section{Resumen}

Objetivo: Identificar las creencias relacionadas con el uso de antidiabéticos orales en personas con diabetes mellitus tipo 2 , con base en la Teoría de la Conducta Planificada. Método: Estudio descriptivo, con abordaje cuantitativo y cualitativo, realizado con 32 participantes en tratamiento con antidiabéticos orales. Los datos se recolectaron por medio de un formulario con preguntas abiertas y se los analizó por la cantidad de emisiones y el contenido. Resultados: Entre las creencias comportamentales se destacan las siguientes: (a) como ventaja, mantener controlada la diabetes; y (b) como desventajas, dolor y malestar gástrico, náusea y diarrea. En las creencias normativas sobresalió la familia como referente social (hijos, madre y hermanos). En cuanto a las creencias de control, tomar los comprimidos con agua y el tamaño de los comprimidos se destacaron como facilidades y dificultades, respectivamente, en relación con el seguimiento de la terapia oral. Conclusión e implicaciones para la práctica: Fue posible identificar las creencias con respecto a la conducta en el uso de antidiabéticos orales que ayudarán a fomentar estrategias educativas con el potencial de fortalecer las creencias positivas y revertir las negativas, en beneficio de la adhesión a la terapia medicamentosa, del control de la glicemia y de la calidad de vida.

Palabras clave: Creencias; Conducta; Diabetes mellitus tipo 2; Tratamiento farmacológico.
Corresponding author:

Bernadete de Lourdes André Gouveia. E-mail: bernagouveia46@gmail.com

Submitted on 05/20/2019.

Accepted on 08/12/2019.

DOI: 10.1590/2177-9465-EAN-2019-0148 


\section{INTRODUCTION}

Pharmacological treatment, especially oral antidiabetic (OAD) use, associated with lifestyle changes, is essential to control the metabolism of individuals with type 2 diabetes mellitus (T2DM), to prevent or delay complications, to control clinical stability and, consequently, to improve quality of life. ${ }^{1}$

Medication adherence is defined as the moment in which a patient takes the medication prescribed by a health professional, considering time schedule, doses and duration of treatment. ${ }^{2}$ However, evidence points to low adherence of people with T2DM in following the established medication therapy. ${ }^{3,4}$

Low or non-adherence to the treatment of chronic diseases such as diabetes ranges from $6 \%$ to $55 \% .^{5}$ The literature shows that individuals with lower schooling and younger people present an ineffective adherence to the treatment. ${ }^{5} \mathrm{~A}$ research developed in Ghana has indicated that $38.5 \%$ of the participants adhered to the regular use of the OAD. ${ }^{4}$ Other national research studies that analyzed adherence to antihypertensive treatment and to OAD have reported an adherence of $47 \%$ and $60 \%$, respectively. ${ }^{6,7}$ The prevalence of non-adherent individuals to the established therapy may reach an irreversible gravity, and increased rates of morbimortality and of health public expenses for the treatment.

Factors like adverse reactions, treatment complexity, acute crises of hypoglycemia, high costs of medications, weaknesses in the medication dispensing policy, forgetfulness and difficulties in comprehending the prescription are pointed out as obstacles to therapeutic adherence..$^{3,8-10}$

Considering the relevance of oral therapy follow-up for controlling the metabolism and the disease, it is important to develop health care technologies which benefit and implement self-care actions, supported by theoretical models. From this perspective, the Theory of Planned Behavior (TPB) has been applied to identify, explain and indicate the predictors of behavior in specific contexts. In general, the TPB clarifies that the individual's behavior is determined by the motivation to act, and that they are motivated by behavioral, normative and control beliefs to do so. ${ }^{11}$

While examining the state-of-the-art situation, it is possible to verify few studies based on the TPB about the behavior of individuals with diabetes and the pharmacological treatment. Different aspects seem to influence medication adherence in the distinct scenarios studied. . $^{8-10}$

Therefore, it is essential to gather the beliefs of people with T2DM who support the behavior of taking OAD, considering the sociocultural plurality of the Brazilian context, particularly in the Northeast Region. In this sense, to comprehend the use of OAD in individuals with T2DM to understand the behavioral, normative and control beliefs that influence positively or negatively on the intention of taking the OAD. For this reason, behavioral health studies have been performed in order to understand and intervene appropriately in each context.
In this perspective, the following question arose: What are the beliefs of individuals with T2DM in relation to the use of OAD? In view of the stated above, the objective was to identify the beliefs related to the use of OAD in individuals with type 2 diabetes mellitus, based on the TPB.

\section{THEORETICAL REFERENCE}

The TPB is a theoretical model especially helpful to predict and explain the intention of conducting a behavior. It derives from the social psychology field, which assumes that human beings generally behave in a sensible way to perform an action. ${ }^{11}$ The intention, one of the immediate antecedents of the behavior, is determined by three factors: attitude, made up of the behavioral beliefs; subjective norms, constituted by the normative beliefs; and perceived behavioral control, composed by the control beliefs. ${ }^{11,12}$

The beliefs represent the knowledge individuals have about a certain behavior: its probable consequences in performing the action, the normative expectations of the others and the potential practicalities or impediments to its performance. The beliefs emerge from an "instantaneous" cognitive thought that motivates the attitude and the intention to conduct a behavior. ${ }^{11}$ Thus, the salient beliefs are presented, immediately, when activated on the behavior of interest. ${ }^{11}$

The behavioral beliefs, factors of a personal nature, are related to positive and negative evaluations of an individual to perform an action. The normative beliefs, of a social character, refer to external pressure, that is, the motivation or influence each individual receives from their closest social representatives to conduct a certain behavior. The control belief component refers to the degree of control individuals have about a practicality or a difficulty to perform a certain behavioral action. In other words, the personal will of each individual to reach a goal is sometimes subjected to external or internal influences. ${ }^{12}$

Among the internal factors that may hinder the execution of the behavior are absence of information and lack of the abilities or skills necessary to realize an action. The external or situational factors which project as obstacles can be the following: time, opportunities and dependence on other people. ${ }^{12}$

In this context, the definition of the behavior to be studied comprehends four aspects: action, objective, context and time. ${ }^{11,12}$ The action is defined as the use of OAD among patients with T2DM, the objective intends to identify the beliefs of using OADs, the context is the endocrinology outpatient clinic, and the time take oral antidiabetic drugs in the near 30 days. In this way, it is indispensable to identify the beliefs because, from them, it is possible to identify the psychosocial determinants of the behavioral intention and of the behavior of interest. 


\section{METHOD}

A descriptive, exploratory and cross-sectional study, with quantitative and qualitative approaches, conducted in a university hospital in the endocrinology outpatient clinic, benchmark in the State of Paraíba, from December 2017 to January 2018. The target audience of the study on beliefs was constituted by individuals diagnosed with T2DM, at that time patients of the outpatient clinic of the selected hospital.

According to recommendations of the theoretical model, there is no requirement as for the number of participants to gather the beliefs about a behavior. Nonetheless, a number necessary to reach the saturation criterion of the emitted answers is suggested, that is, when the speeches are repeated and do not add new information or no other theme arises, thus allowing the stop the research. ${ }^{13}$ Therefore, in this investigation saturation of answers was reached with the statements of 32 participants.

Selected for convenience, the sample was constituted by 32 participants who met the following inclusion criteria: individuals over 18 years old, diagnosed with T2DM, in outpatient follow-up and using OAD for a minimum period of six months. The determination of six months in treatment is justified by guaranteeing the building up of beliefs about the behavior in this interval of experience. Individuals using insulin therapy associated with the OAD and people who presented cognitive barriers confirmed in the medical records did not participate of the study.

Data was collected by means interviews carried out by the researcher, in a private room, with the application of a structured form with six open questions and space to register all the answers. The researcher read each question and wrote the answers. The option to collect data using a form arises from the possibility of the researcher to read and write the answers of participants with difficulties in reading or writing. The interview was always performed before a medical appointment scheduled with a health professional. It is emphasized that each interview involved an average duration of 25 minutes.

For data collection, two form-type instruments were applied. The first one was related to socio-demographic characterization (age, gender, race, marital status, origin, schooling, work situation and income), clinical (diagnosis time, glycated hemoglobin, risk factors, presence of comorbidities, pharmacotherapy in use) and healthy habits (physical activities and nutritional follow-up) variables, all consulted in the medical records.

The second form was created according to the recommendations of the theoretical model ${ }^{11,14}$ and evaluated by members of the research groups in chronic diseases. To gather the behavioral beliefs, the following questions were formulated: 1) In your opinion, what are the advantages of taking tablets for diabetes according to the prescription, in the next 30 days? 2) In your opinion, what are the disadvantages of taking diabetes tablets according to the prescription, in the next 30 days? The normative beliefs were evaluated with the following questions: 3 ) Who are the people you consider important and think that you should take diabetes the diabetes tablets according to the prescription, in the next 30 days? 4) Who are the people you consider important that think you should not take the diabetes tablets according to the prescription, in the next 30 days? Finally, the questions to gather control beliefs were the following: 5) In your opinion, what are the practicalities of taking the diabetes tablets according to the prescription, in the next 30 days? 6) In your opinion, what are the difficulties of taking the diabetes tablets according to the prescription, in the next 30 days?

In relation to data analysis, descriptive statistics was used for sample characterization. Results obtained by the open questions form were transcribed and analyzed according to the recommendation of the TPB. ${ }^{11,13}$ The beliefs were organized and categorized by the criterion of similarity (behavioral, normative and control beliefs). For this study, beliefs mentioned five times or more, following the highest citation criterion, that is, those which obtained the highest number of emissions, considering those with a frequency from $10 \%$, and with a final sum above $75 \%$, were considered as salient beliefs according to the recommendations of the theoretical model. ${ }^{11,13}$

The study was authorized by the Research Ethics Committee (REC) with Opinion No. 2.446.500 of 12/17/2017. It is emphasized that all the participants signed the Free and Clarified Consent Term, respecting the national and international rules of research with human beings.

\section{RESULTS}

32 individuals with T2DM participated in this study, mostly females, with an average of 59.06 years old, with a standard deviation of 11.08 , varying from 30 to 77 years old. 20 (62.5\%) participants defined themselves as not white; 17 (53.1\%) were born in other cities, married or in a stable union; illiterate or with incomplete elementary school: 16 (50\%), not active (unemployed or retired): 26 (81.3\%), with an income up to two minimum wages: $25(78.1 \%)$.

With regards to the clinical characteristics, the time of diagnosis varied from 1 to 30 years with an average of 7 years and standard deviation 1.34. In relation to the glycated hemoglobin value of the last three months, evaluated by registration in medical records, the average was of 6.57 , with a standard deviation of 1.02 . With respect to healthy habits, $16(50 \%)$ did physical activities and only eight (25\%) did nutritional follow-up.

As for the chronic diseases associated to T2DM, systemic arterial hypertension was identified in 22 (68.7\%) and hypothyroidism in 3 (9.3\%). Among diabetes complications, three $(9.3 \%)$ individuals presented peripheral neuropathy (foot amputation due to diabetes); two (6.25\%) presented nephropathy; two $(6.25 \%)$ had retinopathy; and two $(6.25 \%)$, heart disease. In relation to the use of other medications with the OAD, the use of anti-hypertensives was noticed in $22(68.7 \%)$ individuals, as well 
as other drugs such as cardiotonics, gastric protector, peripheral vasodilator, hormonal therapy and Vitamin $D$.

Regarding the behavioral beliefs, a total of $49(100 \%)$ beliefs were emitted. Of them, $46(93,9 \%)$ were salient beliefs, with "to keep diabetes controlled" standing out with regards to taking oral medication. Among the disadvantages, "gastric pain and discomfort, nausea and diarrhea" was the most frequent belief. It was noticed that 18 (56.25\%) participants did not emit any belief of disadvantages when taking the OAD for diabetes control, as shown in Table 1.

Table 2 shows the normative beliefs (positive referents) that exerted pressure on the participants about the use of OAD. Three important social groups that influenced the behavior of taking the OADs were identified, namely: family, including children, mother and siblings; husband/wife and doctor. The referent "family" had a greater representation to establish significant pressure on the behavior of taking the OAD, with 19 (43.2\%) emissions.

The self-reference of $6(12 \%)$ cannot be considered as a social referent, although having obtained a frequency above five emissions because the patient must not be considered their own social referent.

In this research, there were not negative referents identified by the selection criterion defined in five emissions, corresponding to a value equal or superior to $10 \%$ of frequency. Consequently, $23(69.7 \%)$ participants informed that there was not any important person who exerted pressure against the behavior of using the OADs.

Table 3 presents the control beliefs (practicalities and difficulties). We noticed a total of $46(100 \%)$ facilitating behavioral beliefs, and 38 ( $82.6 \%)$ were selected as salient modal ones, from which "taking the tablets with water" obtained the highest percentage: $21(45.7 \%)$. With respect to the beliefs of difficulties, a sum of $24(100 \%)$ was presented and, from these, $23(95,8 \%)$ made up the salient modal ones, with "the size of the tablet - big" standing out and being emitted 11 times $(45.8 \%)$, as the biggest obstacle for taking the OADs.
Table 2. Positive normative beliefs in relation to taking the tablets for T2DM. Paraíba, Brazil, 2018

\begin{tabular}{lcc}
\hline \multicolumn{3}{c}{ Normative beliefs } \\
\hline Positive referents & $\mathbf{n}$ & $\%$ \\
\hline Family (children, mother, siblings) & 19 & 43.2 \\
\hline Husband/Wife & 08 & 18.2 \\
\hline Doctor & 06 & 13.6 \\
\hline The patients themselves & 06 & 13.6 \\
Friends & 03 & 6.8 \\
God & 01 & 2.3 \\
Does not have/Does not need & 01 & 2.3 \\
Total & 44 & 100 \\
*PMSNB & 39 & 88.6 \\
\hline * Positive modal salient normative beliefs. & &
\end{tabular}

\section{DISCUSSION}

The research gathered the beliefs related to the intention of individuals with T2DM of both genders to take the OADs, with predominance of women in the sample. Identifying the salient modal beliefs will be extremely important to sponsor a new study about the psychosocial factors determinant to the intention of using the OADs, in order to develop strategies of educational intervention to encourage the change of the negative behaviors and the strengthening of the positive ones, in the promotion of health for the population with T2DM.

In the behavioral beliefs analysis of this study, the reporting of the advantages when taking the tablets for diabetes is favorable to the treatment. These advantages are keeping diabetes controlled, treatment practicality, improving health and not needing to use insulin. In previous studies similar beliefs were obtained. ${ }^{3,8}$ The individuals' confidence in the established pharmacological therapy lies in obtaining controlled blood sugar levels, in the time flexibility for taking the OADs and in

Table 1. Positive and negative behavioral beliefs in relation to taking tablets for T2DM. Paraíba, Brazil, 2018

\begin{tabular}{|c|c|c|c|c|c|}
\hline \multicolumn{6}{|c|}{ Behavioral beliefs } \\
\hline Benefits & $\mathbf{n}$ & $\%$ & Disadvantages & $\mathbf{n}$ & $\%$ \\
\hline To keep diabetes controlled & 24 & 49 & Gastric pain and discomfort, nausea and diarrhea & 08 & 36.4 \\
\hline Practicality in the treatment & 09 & 18.4 & Forgetting to take the medication & 06 & 27.3 \\
\hline To improve health & 08 & 16.3 & Does not control diabetes & 05 & 22.7 \\
\hline Does not need to take insulin & 05 & 10.2 & High cost of the medication & 01 & 4.5 \\
\hline To be healed & 02 & 4.1 & Risk of complication & 01 & 4.5 \\
\hline To be confident & 01 & 2.0 & Many tablets & 01 & 4.5 \\
\hline Total & 49 & 100 & Total & 22 & 100 \\
\hline *SMBB & 46 & 93.9 & *SMBB & 19 & 86.4 \\
\hline
\end{tabular}

* Salient modal behavioral beliefs. 
Table 3. Positive and negative control beliefs in relation to taking the tablets for T2DM. Paraíba, 2018

\begin{tabular}{|c|c|c|c|c|c|}
\hline \multicolumn{6}{|c|}{ Control beliefs } \\
\hline Facilities & $\mathbf{n}$ & $\%$ & Difficulties & $\mathrm{n}$ & $\%$ \\
\hline Taking the tablets with water & 21 & 45.7 & Size of the tablet (big) & 11 & 45.8 \\
\hline Transport in the bag/pocket & 09 & 19.5 & Buying the medication (expensive) & 06 & 25.0 \\
\hline Time schedule to take the tablet (before meals) & 08 & 17.4 & Forgetting to take the tablets (bad memory) & 06 & 25.0 \\
\hline Gratuity of the medication & 04 & 8.7 & Taking the medication every day & 01 & 4.2 \\
\hline Independence to take the medication & 03 & 6.5 & --- & & \\
\hline When the husband remembers & 01 & 2.2 & --- & & \\
\hline Total & 46 & 100 & Total & 24 & 100 \\
\hline *SMCB & 38 & 82.6 & *SMCB & 23 & 95.8 \\
\hline
\end{tabular}

the absence or decrease of the disease symptoms such as polyphagia, weight loss, excessive thirst, frequent urination, malaise, and headache, among others. ${ }^{15}$

The belief identified as the advantage of "not needing to use insulin" when taking the OADs correctly points to the fear of individuals with T2DM in relation to injectable treatment. It is known that the recommendation of treatment for this type of diabetes lies, initially, in changing the lifestyle, with alteration of food habits and the practice of physical activities. However, due to the difficulty and lack of interest of individuals in following the non-pharmacological treatment, the pharmacological therapy is adopted in isolation or associated with two or more OADs and, more effectively, with the insulin injectable therapy. ${ }^{15}$

In the study in question, the positive behavioral belief of "practicality in the treatment" relates to the fact that the medication is orally administered, a convenient action for everyone who needs to take tablets daily. A previous study identified the distribution policy of free medications by the SUS as a practicality to follow the treatment, as well as the practicality of taking the medication. ${ }^{16}$ People with chronic diseases need to adopt, for an unlimited time, the daily use of medications in their routine and, in this context, the established treatment must be flexible regarding the time schedule, and medications must be easy to take, simple to transport and other practicalities.

In relation to the disadvantages, the most salient belief categorized as unfavorable to the use of the tablets, was pain and gastric discomfort, nausea and diarrhea. Similar beliefs of adverse effects to the use of OAD emerged in previous research studies, with a higher frequency to the one in this study, $(57.7 \%)^{3}$ and $(82.4 \%) .{ }^{8}$ Most of the drugs in the tablet composition for T2DM have benefits because they reduce glycated hemoglobin, without risks of hypoglycemia with weight loss. Nevertheless, they present adverse effects like diarrhea and/or abdominal pain, nausea and vomits, which occur only at the beginning of the treatment, with symptoms decreasing significantly in time and with a possible dose reduction. ${ }^{7}$ The fact that individuals are not being informed about the emergence of the adverse effects of oral therapy favors discontinuance or negligence to the treatment without returning to the reference outpatient clinic first.

With respect to the behavioral belief of disadvantage in which the participants reported forgetting to take the medications, this is not a conscious belief for not taking the tablets following the therapy diagram, on the days and at the times established; however, it is an involuntary behavior for non-adherence, leading to treatment discontinuity. A study on the evaluation of treatment adherence to the use of insulin also evidenced forgetfulness as an obstacle for a non-satisfactory adherence to the treatment as prescribed. ${ }^{17}$

Another investigation, which evaluated the adherence to anti-hypertensive therapy, identified that negligence when taking the medication is associated with the difficulty of adherence. The authors report that medication discontinuity due to forgetfulness leads to pressure oscillations, with negative events. ${ }^{18}$ Domestic tasks associated with work routine are detrimental activities to the responsibility of adopting the behavior of therapy continuation, which results in an abbreviation of the complications of the diabetic neuropathy type.

As a further belief of disadvantage, the participants reported that taking the tablets daily does not control diabetes. This disadvantage is related to the responsibility that the individual places in the pharmacological treatment, ignoring the nonpharmacological self-care actions such as practicing physical activity and a healthy diet, and the recommended lifestyles that must be associated to the pharmacological treatment, since they help to an adequate glucose control. ${ }^{15}$ In addition, factors such as low schooling and poor income found in the sample of this study should be considered in the process of treatment adherence, with a need of orientation regarding the therapeutic regimen. ${ }^{16}$

With respect to the normative beliefs, the social referents of positive influence observed were the closest family members who encouraged the execution of the behavior. It is emphasized that the proximity of family members, children, husband/wife, 
mother and siblings reinforces the connection between care and responsibility with the disease and the treatment. $A$ recent research on self-care in T2DM highlights that the partner influenced positively on the satisfactory self-care behaviors, including the performance of capillary glycaemia, monitoring of feet exam and following the medication therapy. ${ }^{19}$

Participation of family referents should overcome the influence for the behavior and help to comply with the time schedule to take the tablets, especially for those with motion limitations and decreased visual acuity identified in this study, since it reinforces the treatment with blood sugar levels control, minimizing the worsening of the diseases.

The reference of the doctor as a social influent in treatment management shows that there is a connection between this health professional and the patients, a reference that can be associated with a prolonged follow-up, of ten years or more, by the professionals to the interviewees. In a previous study, the doctor and the nursing team were chosen as social influents. ${ }^{8}$ These data partially corroborate the findings of this study, since the nursing team was not mentioned.

The absence of nurses as social referents to the use of OAD in the support network points to the necessity of a higher level of participation in conducting the adequate treatment for glycemic control. The nursing team needs to develop and incorporate competences to strengthen the intention and the behavior of taking the OADs. ${ }^{19}$ Therefore, it becomes essential to reinforce the connection between assistance and education of health professionals about the disease and the treatment for the sake of the individuals and their families, in order to prevent complications and to minimize the existing ones, such as diabetic neuropathies, which increase suffering and costs with the treatment.

With regards to the social referents that influence negatively on the use of the tablets for T2DM, there was not a significant representation, considering the criterion established for this study to include beliefs with five or more emissions, corresponding to a frequency above $10 \%$. This shows that individuals with T2DM using the OAD and participating in this research did not consider having important people around who exerted an opposing pressure to the treatment prescribed for glucose control.

In relation to the control beliefs that facilitated the behavior of interest, the following were observed: taking the tablets with water, carrying the tablets in a bag or pocket when going out of the house and the time to take the tablets preferably before meals. It can be seen that the freedom to make use of the medications in convenient moments with other tasks allows a certain familiarity among the behaviors, as well as the simplicity of taking the tablets with water, which can occur at home or not, contrary to the use of insulin which demands complex skills during application, in relation to management and knowledge about the injectable procedure. Previous studies identified similar beliefs: taking the medications associated to the temporal markers and carrying them when gong out of the house, both identified as favorable to medication adherence. . $^{3,8,9}$

Still in relation to the control beliefs of taking the tablets, the time to take the medication was identified as favorable to the routine, following mealtime, twice a day (before breakfast and lunch or dinner). The possibility to follow these time schedules is beneficial to the intention of conducting the behavior of taking the OADs, since it alerts as to the obligation to take the tablets, minimizing the damage caused by forgetfulness.

In relation to the beliefs that hinder taking the OAD, the size of the tablets was registered as an obstacle, referred to as "big", complicating the swallowing, which may cause unpleasant sensations like bitter taste and choking. It is worth emphasizing that the reference to this belief of difficulty was presented by female participants in its majority. Difficulty in buying the medication is also found in the sequence of this category of difficulties. When the public health system does not supply it, buying the medication is one of the difficulties pointed out by the participants of this research, since the high cost drugs are not available and need to be paid with own resources. Another study, conducted with people with heart failure, identified the fact of paying for the medication as an obstacle, hindering the adherence to the heart disease treatment. ${ }^{20}$

The medication therapy for T2DM presents a variety of new drugs available in the market; however, the costs to buy these medications are still far from accessible. Among the characteristics of the sample studied, the difficulties related to the resources to buy the medications were inferred. A study on medication adherence among patients with T2DM identified that obtaining medications through health plans contributed to a better adherence, supporting that control beliefs confront with external factors. It is thought that the need to buy the medications may affect the treatment, interrupting the execution of the behavior. ${ }^{4}$

In this study, the negative perception of the participants in relation to taking the tablets for T2DM lies in the need to buy and take these medications for their whole life, without therapeutic possibilities of cure, as well as the need to adopt beneficial habits of practicing physical activities and eating healthy food. For this reason, individuals are discontented having to invest in the treatment and in their health, considering only blood sugar level control.

In relation to forgetting to take the OADs, the results found may be linked to people denying the disease and not being available to continue the treatment, even unconsciously. The literature data point to the fact that forgetfulness is presented as socially acceptable, without any recrimination for the not performed action and, for this reason, is so frequent in the research results. ${ }^{9,10}$ The behavior of forgetting to take the medication was not considered a belief of difficulty or an obstacle to the use of OAD because it is understood as an unconscious action on the part of the individual. Nevertheless, the repetition 
of this conduct can be understood as the little importance the patient gives to the use of tablets for glucose levels control.

A previous study associating patients' beliefs and adherence to the OAD, conducted in a population from China, identified the need of having somebody to remember them to take the OAD as control belief, suggesting that the participants forget to take the medications for the treatment of diabetes. ${ }^{3}$ Still, in the same study, the authors found non-acceptance of the disease and fragility in the medication adherence as obstacles throughout life. Consequently, it is suggested that interventions directed to responsibility and behavior autonomy are implemented to reinforce positive beliefs and to revert the negative ones, thus strengthening the determinant factors of the adherence intention.

Reports of forgetfulness to take the medication, present in this and in others studies, can be minimized with alert strategies by means of technological applications, and in a simpler way with warnings in the main co-living spaces at home and at work and, apart from that, attention to the pharmacological diagram, with a fixed dose and a reduced frequency of ingestion with another two drugs, which may contribute to adherence.

The absence of studies based on the TPB and on chronic diseases in the health area is signaled in the Brazilian context, which hinders comparisons or corroboration of the findings. Consequently, new studies involving the chronic diseases are suggested to discover the beliefs related to adherence to the pharmacological and non-pharmacological treatments.

\section{CONCLUSION AND IMPLICATIONS FOR THE PRACTICE}

It is understood that identifying behavioral, normative and control beliefs in relation to the use of the OAD in individuals with T2DM is important to specify the fragilities of facing the treatment, in relation to the advantages and practicalities, the disadvantages and the obstacles of oral treatment, with the potential to strengthen the positive beliefs and to revert the negative ones, with benefits found in blood sugar levels control, in order to minimize clinical emergences and repeated hospitalizations due to acute hyperglycemic crisis, as well as to delay the chronic complications.

Study limitations are related to the specificities in the research scenario; therefore, it is prudent that new investigations in new samples and wider contexts are conducted, since this is a human behavior subjected to the influence of internal and external sociocultural influences, thus being impossible to generalize the proposed objective.

It is recommended to direct strategies of educational intervention that reinforce the beneficial variables to the behavior and revert positively the negative factors that affect health promotion. Comprehending and intervening in the difficulties faced by individuals with diabetes related to the use of the OAD is revealed as important for the practical assistance of nursing and health teams. Motivational strategies must be thought and established, from a regional context, in order to boost both the proposed therapeutic adherence and quality of life.

\section{REFERENCES}

1. American Diabetes Association. Type 2 Diabetes - Basics [Internet] Arlington, VA: American Diabetes Association; 2017; [cited 2019 jan 02]. Available from: http://www.diabetes.org/diabetes-basics/type2/?loc=util-header_type2

2. Cramer JA, Roy A, Burrell A, Fairchild CJ, Fuldeore MJ, Ollendorf DA, Wong PK. Medication compliance and persistence: terminology and definitions [Internet]. Value Health. 2008 jan/feb; [cited 2019 aug 03]; 11(1):44-7. Available from: https://www.ncbi.nlm.nih.gov/ pubmed/18237359

3. Wu P, Liu N. Association between patients' beliefs and oral antidiabetic medication adherence in a chinese type 2 diabetic population. Patient Prefer Adherence [Internet]. 2016 jun; [cited 2018 nov 13]; 10:11611167. Available from: https://www.ncbi.nlm.nih.gov/pmc/articles/ PMC4930230/

4. Bruce SP, Acheampong F, Kretchy I. Adherence to oral anti-diabetic drugs among patients attending a Ghanaian teaching hospital Pharm Pract (Granada) [Internet]. 2015 jan/mar; [cited 2018 nov 13] 13(1):533. Available from: https://www.ncbi.nlm.nih.gov/pmc/articles/ PMC4384271/

5. Ayres LR, Ade OB, Borges AP, Pereira LR. Adherence and discontinuation of oral hormonal therapy in patients with hormone receptor positive breast cancer. Int J Clin Pharm [Internet]. 2014 feb; [cited 2019 may 11]; 36(1):45-54. Available from: https://www.ncbi.nlm. nih.gov/pubmed/23934310

6. Aquino GA, Cruz DT, Silvério MS, Vieira MT, Bastos RR, Leite ICG Fatores associados à adesão ao tratamento farmacológico em idosos que utilizam medicamento anti-hipertensivo. Rev Bras Geriatr Geronto [Internet]. 2017 feb; [cited 2019 may 11];20(1):111-122. Available from: http://dx.doi.org/10.1590/1981-22562017020.160098

7. Faria HTG, Santos MA, Arrelias CCA, Rodrigues FFL, Gonela JT, Teixeira CRS, et al. Adesão ao tratamento em diabetes mellitus em unidades da Estratégia Saúde da Família. Rev Esc Enferm USP [Internet]. 2014 Apr; [cited 2019 may 10]; 48(2):257-263. Available from: http://dx.doi. org/10.1590/S0080-623420140000200009

8. Januzzi FF, Rodrigues RCM, Cornélio ME, São-João TM, Gallan MCBJ. Beliefs related to adherence to oral antidiabetic treatment according to the Theory of Planned Behavior. Rev Latino-Am Enfermagem [Internet]. 2014 aug; [cited 2018 aug 09]; 22(4):529-37. Available from: http://www.scielo.br/scielo.php?script=sci_arttext\&pid =S0104-11692014000400529

9. Guénette L, Lauzier S, Guillaumie L, Giguère G, Grégoire JP, Moisan J. Patients' beliefs about adherence to oral antidiabetic treatment: a qualitative study. Patient Prefer Adherence [Internet]. 2015; [cited 2018 aug 09]; 9:413-20. Available from: https://www.ncbi.nlm.nih.gov/pmc/ articles/PMC4362977/

10. Guénette L, Breton MC, Guillaumie L, Lauzier S, Grégoire JP, Moisan J. Psychosocial factors associated with adherence to non-insulin antidiabetes treatments. J Diabet Complications [Internet]. 2016 mar; [cited 2018 aug 09]; 30(2):335-342. Available from: http://dx.doi. org/10.1016/j.jdiacomp.2015.10.016

11. Ajzen I, Fishbein M. Understanding atitudes and predicting social behavior. Englewood Cliffs, NJ: Prentice Hall; 1980.

12. Ajzen I. The theory of planned behavior. Organ Behav Hum Decis Process. [Internet]. $1991 \mathrm{dec}$; [cited 2018 aug 09]; 50(2):179-211. Available from: https://doi.org/10.1016/0749-5978(91)90020-T

13. Francis C, Francis AJJ, Eccles MP, Johnston M, Walker A, Grimshaw J, et al. Constructing questionnaires based on the theory of planned behavior: A manual for health services researchers [dissertation]. Newcastle upon Tyne, UK: Centre for Health Services Research: University of London Institutional Repository; 2004. Available from: http://openaccess.city. ac.uk/id/eprint/1735 
14. Ajzen I. Constructing a Theory of Planned Behavior questionnaire. Brief Description of the Theory of Planned Behavior. 2006. Available from: https://www.researchgate.net/publication/245582784

15. Sociedade Brasileira de Diabetes. Diretrizes - Sociedade Brasileira de Diabetes: 2017-2018 [Internet]. São Paulo (SP): Editora Clannad; 2017; [cited 2019 may 11]. Available from: https://www.diabetes.org. br/profissionais/images/2017/diretrizes/diretrizes-sbd-2017-2018.pdf

16. Tavares NUL, Bertoldi AD, Mengue SS, Arrais PSD, Luiza VL, Oliveira $M A$, et al. Factors associated with low adherence to medicine treatment for chronic diseases in Brazil. Rev Saúde Pública [Internet]. 2016; [cited 2018 nov 17]; 50(Suppl 2):10s. Available from: http://www.scielo.br/ scielo.php?script=sci_arttext\&pid=S0034-89102016000300307

17. Trevizan $\mathrm{H}$, Bueno $\mathrm{D}$, Koppitke L. Avaliação da adesão ao tratamento de pacientes usuários de insulina em uma unidade de atenção primária à saúde. Rev APS [Internet]. 2016; [cited 2018 dec 28]; 19(3):384395. Available from: https://aps.ufjf.emnuvens.com.br/aps/article/ view/2627/1015
18. Albuquerque NLS, Oliveira ASS, Silva JM, Araújo TL. Association between follow-up in health services and antihypertensive medication adherence. Rev Bras Enferm [Internet]. 2018; [cited 2018 aug 09] 71(6):3006-12. Available from: http://www.scielo.br/pdf/reben/ v71n6/0034-7167-reben-71-06-3006.pdf

19. Eid LP, Leopoldino SAD, Oller GASAO, Pompeo DA, Martins MA, Gueroni LPB. Fatores relacionados às atividades de autocuidado de pacientes com diabetes mellitus tipo 2. Esc Anna Nery [Internet].2018; [cited 2018 aug 09];22(4):e20180046. Available from: http://www.scielo. br/pdf/ean/v22n4/pt_1414-8145-ean-22-03-e20180046.pdf

20. Shehab A, Elnour AA, Swaidi SA, Bhagavathula AS, Hamad F, Shehab $\mathrm{O}$, et al. Evaluation and implementation of behavioral and educational tools that improves the patients' intentional and unintentional nonadherence to cardiovascular medications in family medicine clinics. Saudi Pharm J [Internet]. 2016 mar; [cited 2018 aug 10]; 24(2):182-8. Available from: https://www.ncbi.nlm.nih.gov/pubmed/27013911 